\title{
PROCESSOS DE SIGNIFICAÇÃO NO BRINCAR: PROBLEMATIZANDO A CONSTITUIÇÃO DO SUJEITO
}

\author{
Andréa Vieira Zanella* \\ Edla Grisard Caldeira de Andrada
}

\begin{abstract}
RESUMO. Problematizando a constituição do sujeito a partir da análise de um episódio envolvendo dois bebês e uma professora, vídeo gravado em uma creche pública de Florianópolis/SC, procurou-se estudar a gênese dos processos de significação engendrados na situação analisada, observando a dinâmica das relações professora - bebês. Utilizando-se os aportes teóricos da psicologia histórico-cultural, mais especificamente as contribuições de Lev Semionovitch Vygotski, que considera a dupla dimensão do ser humano, sujeito e sujeitado, ressalta-se a importância do Outro no processo de significação e constituição do sujeito, sem deixar de lado a ativa participação do Eu, social e historicamente produzido.
\end{abstract}

Palavras-chave: constituição do sujeito, processos de significação, Psicologia histórico-cultural.

\section{SIGNIFICANCE PROCESSES IN PLAYING TIME: QUESTIONING THE PERSON CONSTITUTION}

\begin{abstract}
Questioning the person constitution from the analysis of an episode involving two babies and a caregiver, video recorded in a public day-care center of Florianópolis/SC, it was studied the genesis of the significance processes, observing the dynamic of the relations caregiver-babies. Based on the theoretical framework of the historical-cultural psychology, especially the contributions of Lev Smionovitch Vygotski, which considers the double dimension of the human being, subject and subjected, the importance of the Other in the process of significance and person constitution is pointed out, but it is also included the active participation of the I, social and historically produced.
\end{abstract}

Key words: person constitution, significance process, historical cultural psychology.

\section{INTRODUÇÃO}

O processo de constituição do sujeito vem sendo investigado por pesquisadores de diferentes orientações teórico-metodológicas em Psicologia, dentre as quais a Psicologia histórico-cultural (Góes, Smolka \& Pino, 1998; Pino, 1995; Zanella, Balbinot \& Pereira, 2000). Esta corrente teórica considera que o sujeito se constitui nas relações com outros, via atividade caracteristicamente ${ }^{1^{3}}$ humana, a qual é necessariamente mediada, seja por ferramentas técnicas seja por ferramentas semióticas ${ }^{2}$.

A dimensão histórica e social, tanto da atividade como do próprio sujeito que a engendra e que por seu intermédio constitui suas características singulares, aponta para a necessidade de a investigação nessa perspectiva teórico-metodológica focar contextos sociais específicos e as relações com outros sujeitos, sejam estes outros concretos ou objetivados nas produções culturais mediadoras da atividade em questão.

\footnotetext{
Universidade Federal de Santa Catarina, Programa de Pós-Graduação da Universidade Federal de Santa Catarina.

Endereço para correspondência: UFSC, CFH, Psicologia, Campus Trindade, 88010-970, Florianópolis-SC. E-mail: andreavz@uol.com.br

\# Psicóloga da Secretaria de Educação e Cultura do Município de São José, Santa Catarina. E-mail: edla@ floripa.com.br

1 Como esclarece Riviére (1985, p.41), o conceito de atividade (deuatel'nost) é central na teoria de Vygotski. O próprio autor esclarece a importância da atividade mediada como categoria explicativa da constituição dos processos psicológicos superiores e da própria consciência (vide Vygotski, 1983, páginas 47 a 96). Esse mesmo conceito foi desenvolvido posteriormente por Leontiév (1975), porém com algumas diferenças, principalmente no que se refere ao que se constitui como objeto de apropriação: para Leontiév, a atividade em si, sendo que para Vygotski o que o sujeito se apropria é da significação da atividade.
}

2 Análises mais aprofundadas encontram-se em Pino, 1995. 
Uma das situações que se apresentam como importantes para a análise do processo de constituição do sujeito é a brincadeira infantil. Rompendo com a visão tradicional de que a brincadeira é atividade natural de satisfação de instintos infantis, Vygotski ${ }^{3}$ (1998) apresenta o brincar como atividade em que tanto significados social e historicamente produzidos são veiculados quanto novos podem ali emergir. Brincar e o jogo de faz-de-conta consistem em "espaço de construção de conhecimentos pelas crianças" (Prado, 1998, p.3) na medida em que os significados que ali transitam são particularmente apropriados. Nesse sentido, a pesquisa sobre essa atividade exerce um papel fundamental para a compreensão do processo de constituição das características singulares dos sujeitos em relação (Rocha, 1997; Coelho \& Pedrosa, 2000).

Partindo desses pressupostos, neste artigo é analisado um episódio videogravado de um momento da relação entre uma professora e alguns bebês em um berçário de uma creche conveniada à rede municipal de ensino da Grande Florianópolis-SC, tendo sido delimitada como foco do presente estudo a atividade de esconder e descobrir o rosto com um pano (uma fralda de boca) e os processos de significação ali envolvidos, brincadeira aqui denominada de "cadê...achou!".

\section{BREVES CONSIDERAÇÕES TEÓRICAS}

Inúmeras pesquisas têm demonstrado que as interações sociais, mais especificamente as relações adulto-criança, supõem participação ativa de ambos, muito embora a maioria das pesquisas que partem de um pressuposto histórico-cultural focalize essa interação concebendo o adulto como o parceiro mais experiente, visto que já se encontra imerso na esfera do mundo simbólico (vide Oliveira, 1995; Góes \& Smolka, 1997; Rossetti-Ferreira, Amorim \& Vitória, 1996).

É certo que nos primeiros momentos de vida do bebê a diferença de performance entre o adulto e o bebê é clara e óbvia. Mesmo que para a mãe, ou adulto responsável, as manifestações do bebê veiculem

3 O alfabeto russo diferencia-se do ocidental, o que explica os variados modos como o nome de Vygotski vem sendo grafado. Duarte (2000, p.2 - nota de rodapé) apresenta as diferentes grafias e seus diferentes usos por pesquisadores americanos, ingleses e espanhóis. Optamos neste trabalho pela grafia espanhola que consta das Obras Escolhidas, à exceção de referências diretas a publicações. Justifica-se assim a não-padronização da grafia do nome do autor. significados, tais significados são resultado das suas experiências anteriores, marcadas socioistoricamente. Em outras palavras, por estar há mais tempo inserida do que o bebê no mundo simbólico, a mãe tem recursos para interpretar os movimentos difusos do bebê, sendo que

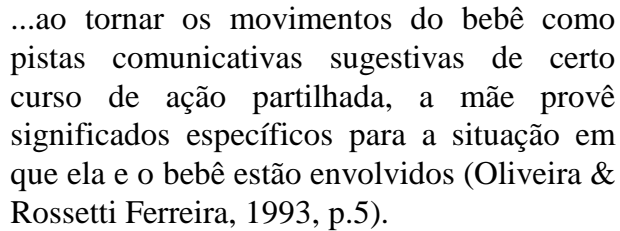

Essa tentativa da mãe e dos outros adultos, de atribuir significados aos movimentos do bebê, faz com que a criança apreenda desde o nascimento significações de seu universo cultural. Desse modo, o que o bebê apropria do mundo passa, inexoravelmente, pelas significações que são impressas ao contexto que o cerca e aos seus próprios movimentos pelas pessoas com as quais convive ${ }^{4}$.

O processo de significação é destacado por Vygotski (1998) em sua teoria da gênese e desenvolvimento do psiquismo humano, posto que, via atividade em contextos sociais específicos, o que é apropriado pelo sujeito vem a ser não a realidade em si, mas o que esta significa tanto para os sujeitos em relação quanto para cada um em particular. Nesse sentido, ressalta-se que esse movimento de apropriação das significações não se dá de maneira passiva nem direta, pois o sujeito reelabora, imprime sentidos privados ao significado compartilhado na cultura e nesse processo apropria-se do signo em sua função de significação, observando o seu duplo referencial semântico:

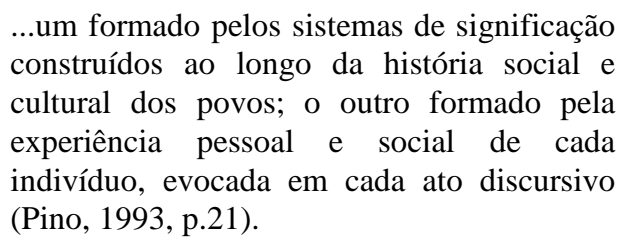

Em outras palavras, já nascemos em um meio cultural repleto de significações social e historicamente produzidas, definidas e codificadas, as quais são constantemente ressignificadas e apropriadas pelos sujeitos em relação, constituindo-se assim como motores do desenvolvimento.

4 Esse processo pode ser mais bem entendido através do exemplo do gesto de apontar (Vygotski, 1983), que este autor apresenta para discutir a internalização das funções superiores (Pino, 1993). 
Necessário se faz esclarecer que para Vygotski o desenvolvimento humano diferencia-se sobremaneira da forma como é entendido por outras teorias psicológicas: este é visto como cultural, como um processo que ocorre orientado para si mesmo, porém necessariamente mediado por um outro, que vem a ser a própria cultura. Nesse movimento constituem-se os processos psicológicos superiores, enfim, a psique humana, entendida nesta perspectiva como inexoravelmente social

\begin{abstract}
...estrutura relacional, ou seja, como uma rede cada vez mais complexa de relações sociais internalizadas, relações em que o indivíduo vai se envolvendo desde o nascimento (Pino, 1996, p.32).
\end{abstract}

Para Vygotsky, o conceito de processo psicológico superior

...está constituído pelos processos de
domínio dos meios externos do
desenvolvimento cultural e do pensamento: o
idioma, a escrita, o cálculo, o desenho; em
segundo lugar, está constituído pelo processo
de desenvolvimento das funções psíquicas
superiores especiais, não limitadas nem
determinadas de nenhuma forma precisa e
que tem sido denominadas pela psicologia
tradicional com os nomes de atenção
voluntária, memória lógica, formação de
conceitos, etc. (Vygotski, 1987, p.32).

Vygotski esclarece ainda que o desenvolvimento humano é um processo dialético, marcado por etapas qualitativamente diferentes determinadas pela atividade mediada, justamente o que o promove. Via atividade o homem (entendido enquanto sujeito genérico) é capaz de transformar sua própria história e a história da humanidade, posto que por seu intermédio transforma o contexto social em que se insere e ao mesmo tempo se transforma.

$\mathrm{O}$ que caracteriza a atividade humana, por sua vez, é o emprego de instrumentos, sejam estes ferramentas ou signos, os quais lhe atribuem um caráter inexoravelmente mediado. Segundo Vygotski, a diferença entre instrumento e signo

\footnotetext{
...consiste nas diferentes maneiras com que eles orientam o comportamento humano. A função do instrumento é servir como um condutor da influência humana sobre o objeto da atividade; ele é orientado externamente ...o signo, por outro lado não modifica em nada o objeto da operação psicológica, constitui um meio de atividade
}

interna dirigida para o controle do próprio indivíduo; o signo é orientado internamente (Vygotski, 1998, p.73)”.

Em se tratando de crianças muito pequenas, cuja percepção está ainda integrada à ação, ou seja, em que toda percepção serve de um impulso para uma ação do bebê (Vygotski, 1998), nota-se que
...os objetos ditam à criança o que ela tem que fazer: uma porta solicita que a abram e fechem, uma escada que a subam, uma campainha que a toquem ...os objetos tem uma força inerente no que diz respeito às ações de uma criança muito pequena... (Vygotski, 1998, p.126).

Dessa forma, os objetos em geral com os quais a criança irá se relacionar são necessariamente objetos significados, portanto comunicáveis e cognoscíveis. A relação estabelecida, no entanto, se modifica: em um primeiro momento é marcada pela predominância de sentidos convencionais, característicos da cultura em que se insere; o objeto, assim, de certa forma diz para a criança como agir. Paulatinamente, no entanto, a relação entre objetos, significado e ação se modifica, sendo que o brincar ocupa um lugar de destaque nessa mudança.

A importância dos brinquedos para o desenvolvimento humano reside no fato de que estes não determinam a ação da criança, pois os objetos perdem sua força determinadora. $\mathrm{Na}$ brincadeira

$$
\begin{aligned}
& \text {...a criança vê um objeto, mas age de maneira } \\
& \text { diferente em relação ao que vê. Assim, é } \\
& \text { alcançada uma condição em que começa a } \\
& \text { agir independentemente daquilo que vê } \\
& \text { (Vygotski, 1998, p.127). }
\end{aligned}
$$

O objeto brinquedo pode, portanto, adquirir para a criança outros sentidos, seja a partir de sua própria ação e imaginação em jogo, seja na intrincada trama de relações que estabelece com os amigos com os quais produz novos sentidos e os compartilha.

Nessa perspectiva, jogar consiste em atividade de crucial importância para o desenvolvimento humano, na medida em que a criança pode transformar e produzir novos significados. Mesmo em crianças muito pequenas é possível observar essa subordinação do objeto em si ao novo significado que lhe é atribuído, o que expressa o caráter ativo da criança no curso do seu próprio desenvolvimento.

A análise desse processo em situações de creche se apresenta como relevante na medida em que se trata de um contexto marcado historicamente pelas 
atribuições de cuidado à infância. As famílias, porém, têm procurado essas instituições hoje em dia interessadas não somente no atendimento às necessidades básicas dos bebês, mas como local que desempenha "funções de caráter mais socializante e pedagógico" (Rossetti-Ferreira, Amorim \& Vitória, 2000, p.119).

De modo geral, é possível afirmar que toda e qualquer instituição de atendimento infantil cumpre esse triplo papel - cuidar, socializar e educar - na medida em que as ações das professoras em relação às crianças, mesmo que centradas nos cuidados básicos, veiculam significados e, portanto, são educativas e constitutivas dos sujeitos em relação (vide Zanella \& Cord, 1999). Portanto, torna-se importante analisar, em situações específicas, como essas atividades acontecem, o caráter que assumem e o lugar que ocupam os sujeitos em relação - professora e bebês no processo de produção, socialização e apropriação de significações. Considerando esses pressupostos é objetivo deste trabalho analisar, a partir de uma situação de brincadeira envolvendo uma professora e alguns bebês, a participação de cada um em relação às significações em trânsito naquele contexto.

\section{MÉTODO}

O contexto investigado consistiu em uma creche que integra um centro comunitário, localizado em um bairro da região central de Florianópolis/SC. A creche é mantida atualmente por várias entidades: Prefeitura Municipal, que paga os salários das 11 professoras; Secretarias Estaduais da Educação e Família, que contribuem com a merenda, e uma parceria com um clube do mesmo bairro, cujo aluguel para uma igreja reverte para o pagamento das 19 auxiliares.

A coleta de dados centrou-se em uma das turmas da instituição, a qual atende 12 crianças de 5 a 12 meses, sob responsabilidade de uma professora e duas auxiliares, uma para cada período do dia. Nesse contexto os bebês recebem o desjejum, almoço, lanche e janta. Além das refeições, o dia-a-dia inclui momentos de sono, higiene, banho, passeio no solário e atividades em sala.

Registradas através de filmagens em VHS, as 12 horas de imagens coletadas nesse período exploratório constituem relevante material, que permite analisar o processo de produção e apropriação de significações no contexto das relações sociais ali entabuladas. Para identificar um momento que pudesse explicitar esse processo adotou-se o seguinte procedimento:
- As fitas foram assistidas, primeiramente, com o intuito de se elaborar um inventário. Este inventário descreveu as situações em termos gerais, demarcando o tempo de duração das situações, assim como os tempos em que elas ocorreram na fita.

- A elaboração do inventário e sua análise permitiram selecionar um episódio em que se evidenciam interações mediadas por uma atividade lúdica.

Trata-se de um momento de brincadeira que envolve uma professora (aqui denominada P1) e dois bebês (chamados de B1 e B2). Na cena aparecem dois outros bebês, de 4 e 5 meses (B3 e B4 respectivamente), e uma outra professora ( $\mathrm{P} 2)$, porém esses não foram considerados protagonistas neste episódio.

B1 e B2 são bebês de aproximadamente 8 meses de idade que moram nos arredores da creche, em condições sociais precárias. Passam o dia inteiro na instituição, chegando à creche em torno de $7 \mathrm{~h} 30 \mathrm{~min}$. De acordo com as regras da instituição, as crianças podem sair a partir das $16 \mathrm{~h}$, mas a maioria dos pais ou responsáveis pegam as crianças após as 17h30min.

P1 é uma jovem professora proveniente de uma condição social melhor que a dos bebês, que cursa pedagogia à noite e trabalha na creche há pouco mais de um ano. Trabalha na creche durante todo o dia, tendo duas horas de descanso para o almoço, e é responsável pelos cuidados e educação de 12 bebês. Conta com a ajuda de duas auxiliares - uma para cada período do dia -, meninas que ainda cursam o ensino médio.

As imagens desse episódio foram transcritas e analisadas à luz dos aportes teóricos da psicologia histórico-cultural, resultando nas reflexões que seguem.

\section{O EPISÓDIO}

O episódio se dá no solário. P1 está sentada num tapete no chão com B3 no colo. B1 e B2 estão sentados próximos, B1 à direita de $\mathrm{P} 1$ e $\mathrm{B} 2$ à sua esquerda, quase em frente. P2 está em pé, fora do tapete. $\mathrm{B} 4$ está à esquerda de $\mathrm{P} 1$, mais atrás desta.

1. A cena inicia quando P1 coloca dois potes de plástico entre B1 e B2. Interessa-se por estes apenas B2, que, engatinhando até os potes, arrasta os dois para si. Bl chora e engatinha para fora do tapete, em direção a $P 2$.

2. P2 entrega um pano com uma chupeta amarrada em uma das pontas para P1, que pegando B1 pelo 
braço a puxa para cima do tapete novamente $e$ coloca a chupeta na boca de B1.

3. B1 levanta e abaixo o pano até que cobre o rosto, logo o pano cai e B1 olha para P1. P1 recoloca a chupeta em B1; B2 brinca com os potes, bate no chão e levanta um deles.

4. B4 alcança um dos potes de B2 e este chora; B1 olha para B2. P1 acaricia o cabelo de B2 e diz "pronto, pronto...

5. Bl coloca o pano na cabeça e deixa cair; coloca de novo e se balança da esquerda para a direita.

6. P1 tira o pano da cabeça de B1, mas este coloca de novo, dessa vez cobrindo todo o rosto; B2 observa, ainda chorando.

7. P1 olha para B1 com o rosto coberto e pergunta: "Cadê B1?". Esta tira o pano do rosto e olha para Pl, que prontamente diz "Achou!".

8. P1 pergunta novamente "cadê B1?" e coloca o pano no rosto desta, Bl tira o pano e olha para P1. B2 observa.

9. P1 coloca o pano novamente no rosto de B1 e repete "cadê $B 1$ ?"

10. B1 retira o pano e olha para P1 que diz "achou!". B2 observa

11. P1 pega o pano de B1 e cobre o rosto de B2, chamando seu nome. B1 observa, olha para Ple depois para $B 2$.

12. P1 ajuda B2 a tirar o pano do rosto e continua chamando o nome de $B 2$.

13. P1 puxa o pano do rosto de B2 e diz "eh...". B1 observa.

14. B2 coloca o pano em seu próprio rosto. B1 observa. P1 diz "cadê B2?"

15. B2 tira o pano sozinha e P1 diz "eh...achou!”. B1 olha para B2 e sorri. B2 repete o movimento rapidamente, $B 1$ olha para o pano e sorri.

Até o turno 6 nenhuma interferência significativa do adulto em relação à atividade de B1 favorece a constituição de nova significação para as ações dos bebês. Para a professora, o pano, em princípio, além de objeto que serve para a higiene, é um utensílio utilizado para segurar a chupeta, ambos os significados já partilhados pela cultura local e pelos bebês, que reconhecem o pano nessas funções, ou seja, sabem pegar a ponta do pano em que está a chupeta e colocá-la na boca, bem como o reconhecem quando utilizado por um adulto para limpá-los após as refeições.

Entretanto, é importante ressaltar que a ação de B1 sinaliza outra significação, de "cobrir o rosto e se esconder", a qual provavelmente foi apropriada pelo bebê em outros contextos e relações. Com a iniciativa de B1, observa-se que os bebês, embora pequenos, participam ativamente da produção das pautas de relação, propondo no caso brincadeiras, chamando o adulto para participar e dar continuidade à sua ação de esconder o rosto com o pano.

A cena continua, no turno 6 , com a participação de P1, que reconhece a significação proposta por B1 e participa da atividade. No turno 11, insere B2 na atividade, socializando para este o significado da brincadeira proposta por B1. Na continuidade, compartilha o objeto - o pano - com os dois bebês, colocando uma ponta no rosto de cada um deles e repetindo o jogo de "cadê...achou!" por mais duas vezes, até que B1 puxa o pano para si e B2 chora, sendo acalmada por P1, que a coloca deitada em sua perna. B1 ainda insiste no jogo, dessa vez colocando e tirando o pano sozinha, porém não obtém resposta da professora. Assim, o jogo acaba e B1 vai até os potes para manipulá-los.

\section{ALGUMAS REFLEXÕES ORIUNDAS DO EPISÓDIO APRESENTADO}

Nota-se nesse pequeno episódio a importância da atuação tanto dos bebês quanto da professora na produção de pautas de relação que, considerando os pressupostos de Vygotsky, se apresentam como constitutivas dos sujeitos em questão. Isso porque, como esclarece Pino (1995, p.23),

...não é o modo de ser do indivíduo que explica o seu modo de relacionar-se, mas são as relações sociais em que este está envolvido que explicam o seu modo de ser.

Se a participação de B1 é destacada na medida em que este apresenta pautas de relação para as pessoas com as quais interage, a mediação do adulto é importante na medida em que compartilha significações e torna o jogo significativo para os bebês. Um pedaço de pano, objeto em discussão, ganha um novo significado para B2 através da ação do adulto, que se pauta em uma significação proposta por B1. A origem desta é difícil precisar, implicaria uma análise de contextos variados dos quais este bebê participa, o que parece uma tentativa de encontrar a ponta de um fio que entrelaça sujeitos, histórias e incontáveis situações.

Do episódio aqui apresentado destaca-se um importante pressuposto da psicologia históricocultural, a saber: que 
...o papel da mediação social no desenvolvimento se configura em termos fortes: o caminho do objeto para a criança e da criança para o objeto passa por outra pessoa (Góes, Smolka \& Pino, 1998, p. 155).

Nesse sentido, Vygotski (1981) defende a idéia de que o outro se apresenta como fundamento da constituição do sujeito, pois "é através do outro que nós próprios nos desenvolvemos" (p.161). É preciso esclarecer, contudo, que esse "Outro" não necessariamente é uma pessoa real, concreta: na perspectiva de Vygotski (1981) refere-se à dimensão social da atividade caracteristicamente humana, a qual implica o fenômeno da sinalização, como relatam Góes, Smolka \& Pino (1998, p.155):

O desenvolvimento de sinais acontece através dos significados atribuídos pelos outros às ações da criança. Ao mesmo tempo, a formação do indivíduo está relacionada à produção de sinais para outros de modo que a pessoa se torna "o que é através do que ela produz para os outros (Vygotski, 1981, p.162).

Se a participação do adulto vem sendo investigada há muito tempo, é imprescindível considerar também a ação da criança no sentido de socializar significações que podem assumir lugar de destaque. Como ressalta Góes, da criança

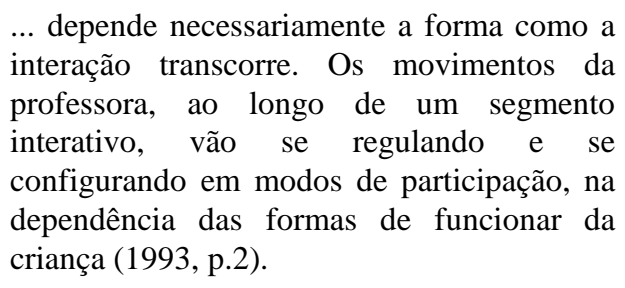

Isso se observa no episódio em análise na medida em que é a própria criança - B1 - que, ao colocar pela primeira vez o pano em sua cabeça, inicia e sugere de certa forma à professora a brincadeira de "cadê...achou!". A professora, por sua vez, significa o gesto de cobrir a cabeça com o pano como brincadeira e a elege como mote para as relações com os bebês.

Assim, percebe-se a dialética do processo de desenvolvimento humano que, mediado pelas significações da atividade nas relações humanas, revela que as relações estão intrinsecamente ligadas e que não podem jamais ser consideradas separadas e independentes. Da mesma forma, as relações sociais não podem ser percebidas como processos definidores e causais, do tipo em que se prevê uma ação em função da ação de outro sujeito. Mesmo não se prevendo ações, nessa estrutura, o Outro será sempre um formador do Eu, pois na medida em que o Eu imita o Outro, se opõe ou a este adere, dialeticamente o "expulsa" para fora de si, não sendo jamais a sua cópia.

\section{REFERÊNCIAS BIBLIOGRÁFICAS:}

Coelho, M.T.F. \& Pedrosa, M.I. (2000). Faz-de-conta: construção e compartilhamento de significados. Oliveira, Z. (Org) A criança e seu desenvolvimento: perspectivas para se discutir a educação Infantil. (pp.51-63). São Paulo: Cortez.

Duarte N. (2000) Vygotski e o Aprender a Aprender: crítica às apropriações neoliberais e pós-modernas da teoria vigotskiana. São Paulo: Ed. Autores Associados.

Góes, M.C. (1993). Os modos de participação do outro nos processos de significação do sujeito, Temas em Psicologia, $1,1-5$.

Góes, M.C.R. \& Smolka, A.L.B. (Org) (1997) A significação nos espaços educacionais: interação social e subjetivação. São Paulo: Papirus.

Góes, M.C.; Smolka, A.L.\& Pino, A. (1998). A constituição do Sujeito: uma questão recorrente?. Em Wertsch, P. Delrio \& Alvarez. Estudos Socioculturais da Mente. (pp. 143-158). Porto Alegre: Artes Médicas.

Leontiév, A. (1975) O Desenvolvimento do Psiquismo. Lisboa: Horizonte Universitário.

Oliveira, Z.M.R. (Org) (1995) Educação Infantil: muitos olhares. 2. ed. São Paulo: Cortez.

Oliveira, Z. \& Rossetti-Ferreira, M.C. (1993) O Valor da Interação criança-criança em creches no desenvolvimento infantil. Cadernos de Pesquisa. 87, 62-70.

Pino, A. (1993) Processos de significação e constituição do sujeito, Temas em Psicologia. 1, 17-23.

Pino, A. (1995). Semiótica e cognição na perspectiva sócio cultural, Temas em Psicologia. 2, 31-39.

Prado, P. (1998) Educação e cultura Infantil em Creche: um estudo sobre as brincadeiras de crianças pequenininhas em um CEMEI de Campinas/SP. Campinas. Dissertação de Mestrado, Unicamp.

Riviére, A. (1985) La Psicología de Vygotski. Madrid: Visor Libros - Infancia y Aprendizaje. (pp. 41-48).

Rocha, M.S. (1997) O Real e o Imaginário no faz-de-conta: questões sobre o brincar no contexto da pré-escola. Em: Smolka, A. e Góes, M. (Orgs.), A Significação nos Espaços Educacionais: interação social e subjetivação. (pp.63-83) São Paulo: Papirus.

Rossetti-Ferreira, M.C; Amorin, K.S. \& Vitória, T. (1996) Emergência de novos significados durante o processo de adaptação de bebês à creche. Em Pedrosa, M.I. (Org.), Investigação da criança em interação social, Coletâneas $d a$ ANPEPP. 4 (1), 111-144.

Rossetti-Ferreira, M.C., Amorin, K.S \& Vitória, T (2000) Rede de significações: perspectivas para análise da inserção de bebês na creche. Cadernos de pesquisa. 109, 115-144. 
Vygotski, L.S. (1981). The genesis of higher mental function Em: Wertsch, The concept of activity in Soviet psychology. (pp. 144-188). New York: Sharpe.

Vygotski, L.S. (1983) Obras Escojidas III. Moscú: Aprendizaje Visor.

Vygotski, L.S. (1987). Historia del desarollo de las funciones Psíquicas Superiores. La Habana/Cuba: Ed.CientíficoTécnica.

Vygotski, L.S. (1998). A Formação Social da Mente. 6. ed. São Paulo: Martins Fontes.

Zanella, A.; Balbinot,G. \& Pereira, R.S. (2000) A renda que enreda: analizando o processo de constituir-se rendeira. Educação e Sociedade, 71, 235-252.
Zanella, A.V.; Cord, D. (1999). Tia, o Tunico me bateu: considerações sobre a violência infatil no contexto da creche. Em Educação subjetividade e poder, v. 6, Porto Alegre: Unijuí, UFRGS, pp. 99-106.

Recebido em 20/08/2002

Revisado em 08/11/2002

Aceito em 15/11/2002 